\title{
Pathologically confirmed autoimmune encephalitis in suspected Creutzfeldt-Jakob disease
}

\section{OPEN}

Peter Maat, MD

Janet W. de Beukelaar, $\mathrm{MD}, \mathrm{PhD}$

Casper Jansen, MD, PhD

Maaike Schuur, MD,

$\mathrm{PhD}$

Cornelia M. van Duijn, $\mathrm{PhD}$

Marleen H. van

Coevorden, MD

Esther de Graaff, PhD

Maarten Titulaer, MD, $\mathrm{PhD}$

Annemieke J. Rozemuller, $\mathrm{MD}, \mathrm{PhD}$

Peter Sillevis Smitt, MD, $\mathrm{PhD}$

Correspondence to Dr. Sillevis Smitt: p.sillevissmitt@erasmusmc.nl

Supplemental data at Neurology.org/nn

\section{ABSTRACT}

Objective: To determine the clinical features and presence in CSF of antineuronal antibodies in patients with pathologically proven autoimmune encephalitis derived from a cohort of patients with suspected Creutzfeldt-Jakob disease (CJD).

Methods: The Dutch Surveillance Centre for Prion Diseases performed 384 autopsies on patients with suspected CJD over a 14-year period (1998-2011). Clinical information was collected from treating physicians. Antineuronal antibodies were tested in CSF obtained postmortem by immunohistochemistry on fresh frozen rat brain sections, by Luminex assay for the presence of wellcharacterized onconeural antibodies, and by cell-based assays for antibodies against NMDAR, $\mathrm{GABA}_{\mathrm{B}} \mathrm{R} 1 / 2, \mathrm{GABA}_{\mathrm{A}} \mathrm{R}$ GLUR1/2, LGI1, Caspr2, and DPPX.

Results: In 203 patients, a diagnosis of definite CJD was made, while in 181 a variety of other conditions were diagnosed, mainly neurodegenerative. In 22 of these 181, the neuropathologist diagnosed autoimmune encephalitis. One patient was excluded because of lack of clinical information. Inflammatory infiltrates were predominantly perivascular and consisted mainly of T cells. The predominant locations were basal ganglia and thalamus (90\%) and temporal lobes and hippocampus (81\%). In 6 patients (29\%), antineuronal antibodies were detected in postmortem CSF, directed against $\mathrm{Hu}, \mathrm{NMDAR}, \mathrm{GABABR} 1 / 2, \mathrm{Caspr} 2$, and an unidentified synaptic antigen in 2. The most frequent symptoms were dementia (90\%), gait disturbance (86\%), cerebellar signs (67\%), and neuropsychiatric symptoms (67\%). Immunopathologic and clinical findings did not differ between autoantibody-negative patients and patients with antineuronal antibodies.

Conclusions: It is important to consider immune-mediated disorders in the differential diagnosis of rapidly progressive neurologic deficits. Neurol Neuroimmunol Neuroinflamm 2015;2:e178; doi: 10.1212/NXI.0000000000000178

\section{GLOSSARY}

CJD = Creutzfeldt-Jakob disease; DSCPD = Dutch Surveillance Centre for Prion Diseases; DWI = diffusion-weighted imaging; IVIg = IV immunoglobulin; NSA-Abs = antibodies directed against neuronal surface antigens; $\mathbf{s C J D}=$ sporadic Creutzfeldt-Jakob disease.

Autoimmune encephalitis and sporadic Creutzfeldt-Jakob disease (sCJD) may present with similar clinical, radiologic, electrophysiologic, and laboratory findings. ${ }^{1-4}$ In $\mathrm{sCJD}$, the course of disease is fatal, while autoimmune encephalitis associated with antibodies directed against neuronal surface antigens (NSA-Abs) usually responds well to treatment.,

We encountered several patients with rapidly progressive dementia diagnosed as possible or probable sCJD, who at autopsy at the Dutch Surveillance Centre for Prion Diseases (DSCPD) turned out to have had potentially treatable autoimmune encephalitis. We retrospectively reviewed all prion-negative autopsy brain reports from the DSCPD to determine the number of pathologically confirmed cases of autoimmune encephalitis in a cohort of patients with

\footnotetext{
From the Departments of Neurology (P.M., J.W.d.B., M.H.v.C., M.T., P.S.S.) and Epidemiology (M.S., C.M.v.D.), Erasmus MC, Rotterdam; Dutch Surveillance Centre for Prion Diseases (C.J., A.J.R.), Department of Pathology, University Medical Center Utrecht; Department of Biology (M.H.v.G., E.d.G.), Division of Cell Biology, Utrecht University; and Department of Neurology (J.W.d.B.), Albert Schweitzer Ziekenhuis, Dordrecht, the Netherlands.

Funding information and disclosures are provided at the end of the article. Go to Neurology.org/nn for full disclosure forms. The Article Processing Charge was paid by Dpt Neurology Erasmus MC.

This is an open access article distributed under the terms of the Creative Commons Attribution-NonCommercial-NoDerivatives License 4.0 (CC BY-NC-ND), which permits downloading and sharing the work provided it is properly cited. The work cannot be changed in any way or used commercially.
} 
suspected sCJD. In addition, we determined the clinical, radiologic, and neurophysiologic characteristics of patients with pathologically confirmed autoimmune encephalitis and examined the CSF for the presence of antineuronal autoantibodies.

METHODS Patients. The DSCPD performed 384 autopsies on patients with suspected Creutzfeldt-Jakob disease (CJD) over a 14-year period (1998-2011). ${ }^{7}$ At brain autopsy, definite CJD was diagnosed in 203 patients based on the presence of spongiosis and positive prion staining. In 181 patients, neuropathology showed a variety of other conditions, mainly neurodegenerative disorders (table e-1 at Neurology.org/nn). In 22 patients, the pathologist identified inflammatory infiltrates consistent with a diagnosis of autoimmune encephalitis. Of these 22 patients, we collected clinical information from treating physicians, including discharge notes, laboratory, neurophysiology, and radiology results. One patient lacked sufficient clinical information and was excluded from the study.

Based on the clinical information, the 21 patients with pathologically proven autoimmune encephalitis were retrospectively classified as probable, possible, or no CJD according to the CDC Diagnostic Criteria for Creutzfeldt-Jakob Disease, 2010 (http://www.cdc.gov/ncidod/dvrd/cjd/resources/CDCs_Diagnostic_ Criteria_for_CJD-2010.pdf).

Standard protocol approvals, registrations, and patient consents. Local ethical committee approval was obtained for research on retained tissues after written informed consent was given by the patients during life or their next of kin after death (Medical Ethics Committee of the University Medical Centre Utrecht 11-531/C). All information was analyzed anonymously.

Antineuronal antibody testing. Postmortem derived CSF samples from all cases were stored at $-80^{\circ} \mathrm{C}$ until testing. As sampling was done postmortem, no serum samples were available at the DSCPD. All CSF samples were tested for autoimmune encephalitis-associated antineuronal antibodies in several assays at a dilution of 1:2. CSF samples were tested on fresh frozen rat brain sections for autoantibodies against neuronal cell surface antigens, as previously described. ${ }^{8}$ Antibodies against the onconeural antigens $\mathrm{HuD}, \mathrm{CDR} 62$ (Yo), $\operatorname{Tr}$ (DNER), amphiphysin, CRMP-5 (CV2), NOVA-1 (Ri), Ma1/2, and Zic4 were assayed, using another immunohistochemistry protocol ${ }^{\circ}$ combined with a recently described multiplex bead-based assay. ${ }^{10}$ In addition, CSF samples were tested on cultured hippocampal neurons and on HeLa cells overexpressing NMDAR1, GABA $A_{B} R 1 / 2, G A B A_{A} R$, GLUR1/2, and DPPX as previously described. ${ }^{9,11}$ Finally, samples were tested in a commercial assay (EUROIMMUN, Lübeck, Germany) for anti-LGI1 and anti-Caspr2 antibodies (previously tested as voltage-gated potassium channel complex antibodies). The sensitive assays on frozen rat brain sections and cultured hippocampal neurons detect clinically relevant (high serum titer) GAD65 and LGI1 antibodies in CSF, rendering underreporting of antibodies by the lack of serum availability unlikely. ${ }^{12}$

Neuropathology. Brains were removed at autopsy and selected tissue samples were immediately frozen and stored at $-80^{\circ} \mathrm{C}$ while the rest of the brain was fixed in formalin and used for histologic and immunologic purposes. Histopathologic examination was performed as described before. ${ }^{7,13}$ In short, relevant sections were stained for $\alpha$-synuclein, ubiquitin, amyloid- $\beta$, and tau in all patients. In a subset of patients, additional immune stainings were carried out for B cells (CD20), T cells (CD3, CD4, and CD8), and macrophages (CD68).

RESULTS Pathology consistent with autoimmune encephalitis was found at autopsy in 22 out of 384 (6\%) patients with clinically suspected CJD, constituting $12 \%(22 / 181)$ of the patients who turned out at autopsy not to have had CJD. Because one patient lacked sufficient clinical information, we present the clinical, pathologic, and serologic findings in 21 patients with pathologically confirmed autoimmune encephalitis. Detailed information on the patients is summarized in tables e-2 and e-3.

Neuropathology. In all 21 patients, inflammatory infiltrates were present (figure e-1). Gliosis was observed in $10(48 \%)$ patients while vasculitis was seen in none. The infiltrates were predominantly perivascular in $15(71 \%)$, predominantly parenchymal in 5 (24\%), and both perivascular and parenchymal in $1(5 \%)$ patient. The infiltrates consisted of CD3positive $\mathrm{T}$ cells in 14/15 (93\%) patients tested. CD8-positive cells were observed in $7 / 8(88 \%)$ and CD4-positive cells in 4/5 (80\%) patients examined. In 8/12 (67\%) patients, CD20-positive B cells were present, mainly in the perivascular infiltrates. CD68positive cells were seen in $11 / 13(85 \%)$ patients.

Infiltrates were mainly located in the basal ganglia and thalamus in $19(90 \%)$, temporal lobes and hippocampus in $17(81 \%)$, cerebellum in $12(57 \%)$, frontal lobes in $11(52 \%)$, other cortical areas in $12(57 \%)$, brainstem in 7 (33\%), and periventricular white matter in 4 (19\%). Neuropathologic changes were far more extensive than MRI changes.

Postmortem CSF testing for antineuronal antibodies. Antineuronal antibodies were detected in 6/21 (29\%) of the postmortem collected CSF samples. Five of these antibodies were directed against NSA. One each was directed against $\mathrm{GABA}_{\mathrm{B} 1 / \mathrm{B} 2}$, NMDAR, and Caspr2, while 2 CSF samples harbored antibodies against an unidentified synaptic antigen (figure 1). One additional sample contained antibodies against the intracellular onconeural $\mathrm{Hu}$ antigen. Of the 4 known antibodies detected in CSF, the Hu antibody had been described long before the time of the patient's illness, while $\mathrm{GABA}_{\mathrm{B} 1 / \mathrm{B} 2}, \mathrm{NMDAR}$, and Caspr2 antibodies were first reported after the death of the respective patients. Three of the 6 patients with antineuronal antibodies presented with limbic encephalitis, 2 with encephalomyelitis, and 1 with Morvan syndrome (associated with anti-Caspr 2 antibodies). Further clinical findings in the 6 patients with pathologically confirmed autoimmune encephalitis and antineuronal antibodies are summarized in table 1 and supplementary information (1). The 

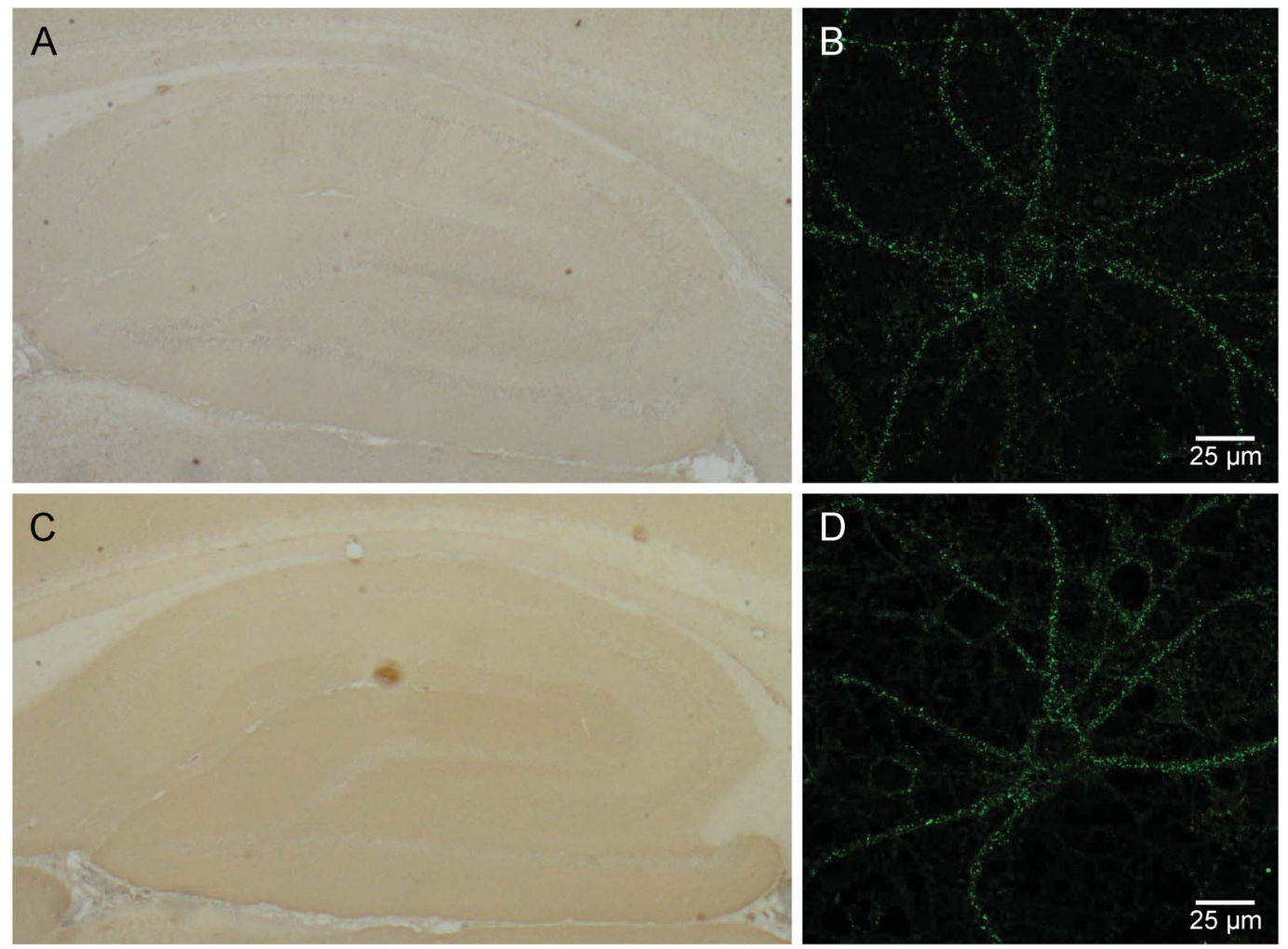

In 2 patients, a synaptic staining pattern in the hippocampus was observed not corresponding to any of the known antigens tested. One patient was a 73-year-old man with limbic encephalitis (A, B; patient 11) and the other a 77-year-old man with encephalomyelitis (C, D; patient 18). Immunohistochemistry was performed as described in the Methods (A, C). To confirm the synaptic staining pattern in these 2 patients, CSF samples were incubated (1:2 dilution) live with primary hippocampal cultures $(B, D)$ as previously described. ${ }^{9}$

phenotypes associated with the known antibodies are classical for these disorders. ${ }^{14}$ The localization and cellular composition of the inflammatory infiltrates found at autopsy did not differ between the antibodypositive and antibody-negative patients (table e-4).

Summarizing, 5/21 (24\%) patients with pathologically confirmed autoimmune encephalitis had CSF autoantibodies directed against NSA (3 against welldefined and 2 against unknown antigens).

Clinical characteristics. All 21 patients with autoimmune encephalitis had a rapidly progressive illness with a median duration of 3.3 months and died within 13 months of first symptoms (table 2, tables e-2 and e-3). In retrospect, 14 of the 21 (67\%) patients with autoimmune encephalitis fulfilled the clinical 2010 CDC criteria for possible or probable sCJD while 7 (33\%) did not. In the subgroup of 6 patients with antineuronal antibody-associated autoimmune encephalitis, $67 \%$ (4 patients) also fulfilled CDC criteria for possible or probable sCJD (table 2). The most frequent main symptoms included dementia (90\%), cerebellar signs (67\%), myoclonus (48\%), and extrapyramidal signs (33\%) (table 3). Other symptoms that were frequently present included gait disturbance (86\%), neuropsychiatric symptoms (67\%), and frontal lobe symptoms (62\%). There were no clear differences in clinical presentation of autoimmune encephalitis with or without detectable antineuronal antibodies in CSF (tables 2 and 3). Only 4 patients received immunotherapy, consisting of steroids in 2, IV immunoglobulins (IVIg) in 1, and both IVIg and steroids in 1 . None of the patients showed substantial improvement and immunotherapy was discontinued in all 4.

Additional investigations. The CSF had been examined in 18 of the 21 patients and was abnormal in 14/18 $(78 \%)$, showing increased protein in $14(78 \%)$, pleiocytosis in $10(56 \%)$, and positive $14-3-3$ protein in 9 (50\%) (table 4).

EEG was performed at least once in 19 of the patients and was abnormal in 18/19 (95\%) with an increase of slow wave activities in 15/19 (79\%). Seven of the patients showed triphasic periodic complexes that were considered compatible with CJD in 6 (32\%). Epileptiform abnormalities were registered in 7 (37\%) of the patients (table 4).

MRI was abnormal in 10/17 (59\%) patients, showing increased signal on T2-weighted or fluid- 


\begin{tabular}{|c|c|c|c|c|c|c|}
\hline Characteristic antibody & \multicolumn{6}{|l|}{ Antigen specificity } \\
\hline Sex/age at onset, y & $\mathrm{M} / 74$ & $\mathrm{~F} / 70$ & $\mathrm{~F} / 49$ & $\mathrm{M} / 55$ & M/77 & $\mathrm{M} / 73$ \\
\hline CJD ${ }^{a}$ & Possible & No & Possible & Possible & Probable & No \\
\hline Onset & Subacute & Subacute & Subacute & Subacute & Subacute & Subacute \\
\hline Classical syndrome & EM & LE & LE & Morvan syndrome & EM & LE \\
\hline Cognitive decline & Yes & Yes & Yes & Yes & Yes & Yes \\
\hline Myoclonus & Yes & No & Yes & No & Yes & Yes \\
\hline Cerebellar signs & Yes & No & No & Yes & Yes & No \\
\hline Disorder of frontal brain & No & Yes & Yes & Yes & Yes & Yes \\
\hline Gait disturbance & Yes & Yes & Yes & Yes & Yes & No \\
\hline Epilepsy & Yes & Yes & Yes & Yes & No & Yes \\
\hline Aphasia & No & Yes & No & No & Yes & No \\
\hline Autonomic dysfunction & Yes & No & No & No & No & No \\
\hline Central hypoventilation & No & No & No & No & No & No \\
\hline CSF cell count & Unknown & 14 WBC & 47 WBC & Unknown & 18 WBC & 8 WBC \\
\hline CSF 14-3-3 & Positive & Not tested & Negative & Negative & Negative & Positive \\
\hline Treatment & No & No & $\begin{array}{l}\text { MP, P, IVIg, } \\
\text { ovariectomy }\end{array}$ & No & No & No \\
\hline Improvement (mRS) & No & No & No & No & No & No \\
\hline Disease duration, mo & 2.6 & 1.5 & 12.3 & 3.3 & 1.3 & 4.7 \\
\hline
\end{tabular}

Abbreviations: CJD = Creutzfeldt-Jakob disease; EM = encephalomyelitis; FLAIR = fluid-attenuated inversion recovery; IVIg = IV immunoglobulin; LE = limbic encephalitis; MP = methylprednisolone; $\mathrm{mRS}=$ modified Rankin Scale; $\mathrm{P}=$ prednisone; $\mathrm{SCLC}=$ small-cell lung cancer; WBC = white blood cells.

${ }^{a}$ Retrospective classification based on clinical information (before autopsy), according to CDC's Diagnostic Criteria for Creutzfeldt-Jakob Disease, 2010 (see Methods).

${ }^{\mathrm{b}}$ Generalized atrophy, periventricular leukoaraiosis, and multiple lacunar lesions.

${ }^{\mathrm{c}}$ Aspecific probably vascular white matter lesions and mild hippocampus atrophy (Scheltens grade II).

attenuated inversion recovery images (table 4). Imaging abnormalities were located in the medial temporal lobes in 3, periventricular in 5 (most likely vascular lesions in 3), basal ganglia and thalamus in 2, and brainstem in 1. None of the patients had MRI changes typical of sCJD, according to 2010 CDC criteria, although most investigations lacked diffusionweighted imaging (DWI) sequences.

The patients with autoimmune encephalitis with antineuronal autoantibodies in their CSF did not clearly differ from the antibody-negative patients in CSF, EEG, or MRI findings (table 4).
Associated tumors. In 9 patients (43\%), a tumor was present. Based on criteria published by an EU consortium, the etiology of the neurologic syndrome could be classified as definitely paraneoplastic in 5 and possibly paraneoplastic in $2 .{ }^{15}$ The tumor was probably unrelated in 2 of the patients, precluding a paraneoplastic etiology. Detailed clinical and oncologic findings are presented in table e-3 and supplementary information (2).

DISCUSSION The first finding of our study is that approximately $7 \%$ of patients with suspected CJD 
Table 2 Clinical characteristics in 21 patients with autoimmune encephalitis and suspected CJD

\begin{tabular}{|c|c|c|c|}
\hline Characteristic & All $(n=21)$ & $\begin{array}{l}\text { CSF antibody } \\
\text { positive }(n=6)\end{array}$ & $\begin{array}{l}\text { No CSF antibody } \\
(\mathrm{n}=15)\end{array}$ \\
\hline Male/female & $15 / 6$ & $4 / 2$ & $11 / 4$ \\
\hline Median (range) age at onset, y & 72 (37-82) & $70(50-77)$ & 72 (37-82) \\
\hline Mean age at onset, y & 68 & 67 & 69 \\
\hline Median (range) disease duration, mo & $3.3(1.0-12.3)$ & 4.4 (1.3-12.3) & $3.3(1.0-11.5)$ \\
\hline Mean disease duration, mo & 4.2 & 4.4 & 4.2 \\
\hline \multicolumn{4}{|l|}{$\begin{array}{l}\text { Diagnosis according to CDC criteria } \\
\text { (2010) for sCJD, } n(\%)\end{array}$} \\
\hline Probable & $8(38)$ & $1(17)$ & $7(47)$ \\
\hline Possible & $6(29)$ & $3(50)$ & $3(20)$ \\
\hline No & 7 (33) & 2 (33) & 5 (з3) \\
\hline
\end{tabular}

Abbreviations: CJD = Creutzfeldt-Jakob disease; $\mathrm{SCJD}=$ sporadic Creutzfeldt-Jakob disease.

have autoimmune encephalitis at autopsy. Secondly, antineuronal autoantibodies could be demonstrated in the CSF from 6 of 21 (29\%) patients with pathologically confirmed autoimmune encephalitis. One case each of anti-Hu, GABA $\mathrm{B}_{1 / \mathrm{B} 2}$, NMDAR, and Caspr2 was detected, while 2 CSF samples had antibodies against an unidentified NSA. Third, in retrospect, $67 \%$ of the patients met the $2010 \mathrm{CDC}$

Table 3 Symptoms in 21 patients with autoimmune encephalitis and suspected CJD

\begin{tabular}{|c|c|c|c|}
\hline & All & CSF antibody positive & No CSF antibody \\
\hline \multicolumn{4}{|l|}{ Main symptoms, n (\%) } \\
\hline Dementia & $19(90)$ & $6(100)$ & $13(87)$ \\
\hline Cerebellar signs & $14(67)$ & $3(50)$ & $11(73)$ \\
\hline Myoclonus & $10(48)$ & $4(67)$ & $6(40)$ \\
\hline Extrapyramidal signs & 7 (33) & 2 (33) & $4(27)$ \\
\hline Akinetic mutism & $5(24)$ & 1 (17) & $4(27)$ \\
\hline Pyramidal signs & $5(24)$ & 1 (17) & $4(27)$ \\
\hline Visual symptoms & $2(10)$ & $1(17)$ & $1(7)$ \\
\hline \multicolumn{4}{|l|}{ Other symptoms, n (\%) } \\
\hline Gait disturbance & $18(86)$ & $5(83)$ & $13(87)$ \\
\hline Neuropsychiatric & $14(67)$ & $5(83)$ & $9(60)$ \\
\hline Apathy/social withdrawal & 8 (38) & 2 (33) & $6(40)$ \\
\hline Agitation/anxiety & $9(43)$ & $4(67)$ & 5 (33) \\
\hline Hallucinations & $5(24)$ & $3(50)$ & 2 (13) \\
\hline Disorder of frontal brain ${ }^{a}$ & $13(62)$ & $5(83)$ & $8(53)$ \\
\hline Epilepsy & 7 (33) & $5(83)$ & 2 (13) \\
\hline Aphasia & $6(29)$ & 2 (33) & $4(27)$ \\
\hline Autonomic dysfunction & $4(19)$ & $1(17)$ & $3(20)$ \\
\hline Central hypoventilation & $2(10)$ & 0 & 2 (13) \\
\hline
\end{tabular}

Abbreviation: CJD = Creutzfeldt-Jakob disease.

${ }^{a}$ Including bradyphrenia, perseveration, utilization, echolalia, and disinhibition. criteria for possible or probable CJD, both in the antibody-positive and antibody-negative group.

Several other studies have addressed the clinical overlap between prion disorders and autoimmune encephalitis. Chitravas et al. ${ }^{3}$ studied prion-negative brain autopsy cases referred to the US National Prion Disease Pathology Surveillance Center. Neuropathology diagnosed an immune-mediated disorder in 26/ $304(8.5 \%)$ of the prion-negative cases with histology, including primary angiitis of the CNS (7), acute disseminated encephalomyelitis (6), limbic encephalitis (6), neurosarcoidosis (4), paraneoplastic cerebellar degeneration (2), and granulomatosis with polyangiitis (Wegener) (1). This study did not report the antineuronal antibody status of the patients. In contrast to our study, most of the misdiagnosed patients did not meet the WHO criteria for CJD.

Grau-Rivera et al. ${ }^{1}$ examined the presence of NSAAbs in the CSF of patients with suspected or pathologically confirmed CJD. NSA-Abs were found in 6 of 346 patients (1.7\%) with a rapidly progressive neurologic disorder suggestive of CJD during life. In contrast to our study, none of these 6 patients met the diagnostic criteria for probable or possible CJD. The target antigens included NMDAR, LGI1, Caspr2, aquaporin $4, \operatorname{Tr}(\mathrm{DNER})$, and an unknown protein. All patients stabilized or improved after appropriate treatment. None of the 49 patients with definite CJD had NSA-abs. Another study reported serum NSAAbs in $<5 \%$ of patients with sCJD, all at very low titers. ${ }^{2}$ In this study, we tested CSF of all patients identified with autoimmune encephalitis at autopsy. CSF is proven more sensitive and specific to detect NSA-Abs as shown for NMDR, ${ }^{16}$ AMPAR, ${ }^{17}$ and $\mathrm{GABA}_{\mathrm{B}} \mathrm{R}^{18}$

In $50 \%$ of our patients with autoimmune encephalitis tested, 14-3-3 protein was elevated in CSF (part of the CDC's 2010 diagnostic criteria), casting further doubt on the usefulness of this test in diagnosing CJD. ${ }^{19}$ EEG was also not useful as triphasic waves were present in $32 \%$ of our autoimmune patients. None of our patients with autoimmune encephalitis showed sCJD-specific MRI abnormalities, supporting the higher specificity of $\mathrm{sCJD}$ MRI criteria over $14-3-3 .{ }^{19,20}$ However, DWI was not performed in most of our patients, and we do not know whether DWI would have retained its specificity in this series. On the other hand, $56 \%$ of patients had an increased leukocyte count $(>5 \times 10 \mathrm{E} 9 / \mathrm{L})$ in their CSF. Although the pleiocytosis was usually mild, it provides a clue to an inflammatory etiology.

Other studies describing clinical overlap between prion and autoimmune disorders focused primarily on rapidly progressive dementia, detecting a $2 \%-$ $9 \%$ prevalence of immune-mediated disorders. ${ }^{21-23}$ In a series of patients with suspected autoimmune 
Table 4 CSF, EEG, and MRI findings in patients with autoimmune encephalitis

\begin{tabular}{|c|c|c|c|}
\hline & All & $\begin{array}{l}\text { CSF antibody } \\
\text { positive }\end{array}$ & $\begin{array}{l}\text { No CSF } \\
\text { antibody }\end{array}$ \\
\hline CSF sampled, $n$ & $18 / 21$ & $6 / 6$ & $12 / 15$ \\
\hline \multicolumn{4}{|l|}{ Protein or cell count, $n$ (\%) } \\
\hline Abnormal & $14(78)$ & $4(67)$ & $10(83)$ \\
\hline Normal & $2(11)$ & 0 & $2(17)$ \\
\hline Not known & $2(11)$ & 2 (33) & 0 \\
\hline \multicolumn{4}{|l|}{ White cell count, $n$ (\%) } \\
\hline Median (range) $\times 10 \mathrm{E} 9 / \mathrm{L}$ & $12(0-47)$ & $16(8-47)$ & $11(0-33)$ \\
\hline Increased (>5 × 10E9/L) & $10(56)$ & $4(67)$ & $6(50)$ \\
\hline Normal & 4 (22) & 0 & 4 (33) \\
\hline Not known & 4 (22) & 2 (33) & $2(17)$ \\
\hline \multicolumn{4}{|l|}{ 14-3-3 protein, n (\%) } \\
\hline Positive & $9(50)$ & 2 (33) & $7(58)$ \\
\hline Negative & $5(28)$ & $3(50)$ & $2(17)$ \\
\hline Not tested & $4(22)$ & $1(17)$ & $3(25)$ \\
\hline EEG performed, $n$ & $19 / 21$ & $6 / 6$ & $13 / 15$ \\
\hline EEG overall abnormal, $n$ (\%) & $18(95)$ & 5 (83) & $13(100)$ \\
\hline Increase in slow wave activities & $15(79)$ & $4(67)$ & $11(85)$ \\
\hline Triphasic periodic complexes & 7 (37) & $3(50)$ & 4 (31) \\
\hline Complexes compatible with CJD & 6 (32) & 2 (33) & 4 (31) \\
\hline MRI performed, $n$ & $17 / 21$ & $6 / 6$ & $11 / 15$ \\
\hline \multicolumn{4}{|l|}{ MRI overall, n (\%) } \\
\hline Abnormal & $10(59)$ & $4(67)$ & $6(55)$ \\
\hline Normal & $7(41)$ & 2 (33) & $5(45)$ \\
\hline \multicolumn{4}{|l|}{ T2/FLAIR increased signal, $n$ (\%) } \\
\hline Yes & $10(59)$ & $4(67)$ & $6(55)$ \\
\hline No & $7(41)$ & 2 (33) & $5(45)$ \\
\hline \multicolumn{4}{|l|}{ Gadolinium enhancement, n (\%) } \\
\hline Yes & 0 & & \\
\hline No & 17 (100) & & \\
\hline
\end{tabular}

Abbreviations: CJD $=$ Creutzfeldt-Jakob disease; FLAIR $=$ fluid-attenuated inversion recovery.

Areas with increased T2/FLAIR signal included periventricular white matter (5), mesiotemporal lobe and hippocampus (3), brainstem (3), basal ganglia and thalamus (2), cortex (2), and internal capsule (1). Generalized atrophy was present in 5 patients, bifrontal atrophy in 2, and hippocampal atrophy in 1.

dementia and good response to immunotherapy, almost $9 \%$ of the disorders had initially been diagnosed as sCJD. ${ }^{24}$ In particular, patients with encephalitis associated with LGI1-Abs may present with myoclonus-like movements and other symptoms that can be mistaken for CJD. ${ }^{4}$

In general, the prognosis of autoimmune encephalitis appears to be determined by the involved immunopathogenic mechanisms. ${ }^{25}$ Disorders accompanied by antibodies directed against intracellular antigens are probably T-cell-mediated and generally respond poorly to immunotherapy. Most paraneoplastic neurologic disorders with onconeural antibodies belong to this category. On the other hand, in disorders associated with NSA-Abs, the antibodies are probably pathogenic and these disorders respond favorably to first- and second-line immunotherapy. Examples include NMDAR, ${ }^{5}$ LGI1, ${ }^{26,27}$ and Caspr $2^{27,28}$ encephalitis. The immunopathology of NSA-Abs-associated encephalitis shows mild to moderate, mainly perivascular, lymphocytic infiltrations containing both $\mathrm{B}$ and $\mathrm{T}$ cells, antibody-producing cells, and immunoglobulin G deposits. ${ }^{29-31}$ It is possible that we missed some cases with burned out or with bland neuropathology and that the 22 cases that we identified represent an underestimation. The encephalitis associated with $\mathrm{Hu}$ or $\mathrm{Ma} 2$ antibodies is characterized by extensive $\mathrm{B}$ and $\mathrm{T}$ cell lymphocytic infiltrations, containing $\mathrm{T}$ cells with a cytotoxic phenotype. ${ }^{31-33}$ In our series, immunopathologic findings did not differ between autoantibody-negative patients and the patients with NSA-Ab (table e-4), nor did clinical, CSF, radiologic, or electrophysiologic characteristics (tables 2-4). The immunopathologic mechanism in the 15 patients with autoimmune encephalitis without detectable autoantibodies remains unclear. It cannot be excluded that some of these patients harbored NSA-Abs that were degraded by postmortem interval or during storage at $-80^{\circ} \mathrm{C}$ in low protein CSF. The lack of serum availability may also have contributed to underreporting of NSA-Abs.

Limitations based on the retrospective nature of the study are applicable. In addition, bias was introduced by the fact that all patients had suspected CJD and had come to autopsy. In particular, the poor outcome with a median survival of 3.3 months (range 1.0-12.3 months) in this study of autoimmune encephalitis was largely determined by this inclusion bias.

It is important to consider both prion and immune-mediated disorders in the differential diagnosis of rapidly progressive neurologic deficits, knowing that EEG and 14-3-3 in CSF do not discriminate sufficiently to distinguish the two. Detection in serum or CSF of specific antineuronal antibodies can establish a diagnosis of autoimmune encephalitis and guide appropriate treatment.

\section{AUTHOR CONTRIBUTIONS}

Study conception: P.M., A.J.R., P.S.S. Study design: P.M., A.J.R., P.S.S. Sample acquisition: C.J., M.S., C.M.v.D., A.J.R. Acquisition of laboratory data: P.M., C.J., M.H.v.C., E.d.G., M.T., A.J.R. Acquisition of clinical data: P.M., J.W.d.B., C.J., M.S., A.J.R., P.S.S. Study supervision, analysis and interpretation of data: M.T., P.S.S. Writing of first draft: P. M., J.W.d.B., P.S.S. Editing and revising final draft for intellectual content: all authors.

\section{STUDY FUNDING}

No targeted funding. 


\section{DISCLOSURE}

P. Maat, J. de Beukelaar, C. Jansen, M. Schuur, C. van Duijn, and M. van Coevorden report no disclosures. E. de Graaf holds a patent for the detection of anti-DNER antibodies. M. Titulaer served on the scientific advisory board for MedImmne LLC, received travel funding from Sun Pharma, is on the editorial board for Neurology: Neuroimmunology of Neuroinflammation, and received research support from Netherlands Organiszation for Scientific Research, ErasmusMC, and Dutch Epilepsy Foundations. A. Rozemuller is on the scientific advisory board for Netherlands Brain Bank and received research support from Neuroscience Campus Amsterdam, Erasmus Mundo. P.S. Smitt holds a patent for the detection of anti-DNER and received research support from Euroimmun. Go to Neurology.org/nn for full disclosure forms.

Received June 22, 2015. Accepted in final form September 23, 2015.

\section{REFERENCES}

1. Grau-Rivera O, Sanchez-Valle R, Saiz A, et al. Determination of neuronal antibodies in suspected and definite Creutzfeldt-Jakob disease. JAMA Neurol 2014;71:74-78.

2. Rossi M, Mead S, Collinge J, Rudge P, Vincent A. Neuronal antibodies in patients with suspected or confirmed sporadic Creutzfeldt-Jakob disease. J Neurol Neurosurg Psychiatry 2015;86:692-694.

3. Chitravas N, Jung RS, Kofskey DM, et al. Treatable neurological disorders misdiagnosed as Creutzfeldt-Jakob disease. Ann Neurol 2011;70:437-444.

4. Geschwind MD, Tan KM, Lennon VA, et al. Voltage-gated potassium channel autoimmunity mimicking CreutzfeldtJakob disease. Arch Neurol 2008;65:1341-1346.

5. Titulaer MJ, McCracken L, Gabilondo I, et al. Treatment and prognostic factors for long-term outcome in patients with anti-NMDA receptor encephalitis: an observational cohort study. Lancet Neurol 2013;12:157-165.

6. Vincent A, Buckley C, Schott JM, et al. Potassium channel antibody-associated encephalopathy: a potentially immunotherapy-responsive form of limbic encephalitis. Brain 2004;127:701-712.

7. Jansen C, Parchi P, Capellari S, et al. Human prion diseases in the Netherlands (1998-2009): clinical, genetic and molecular aspects. PLoS One 2012;7:e36333.

8. Petit-Pedrol M, Armangue T, Peng X, et al. Encephalitis with refractory seizures, status epilepticus, and antibodies to the GABAA receptor: a case series, characterisation of the antigen, and analysis of the effects of antibodies. Lancet Neurol 2014;13:276-286.

9. de Graaff E, Maat P, Hulsenboom E, et al. Identification of delta/notch-like epidermal growth factor-related receptor as the $\operatorname{Tr}$ antigen in paraneoplastic cerebellar degeneration. Ann Neurol 2012;71:815-824.

10. Maat P, Brouwer E, Hulsenboom E, et al. Multiplex serology of paraneoplastic antineuronal antibodies. J Immunol Methods 2013;391:125-132.

11. Maat P, de Graaff E, van Beveren NM, et al. Psychiatric phenomena as initial manifestation of encephalitis by antiNMDA receptor antibodies. Acta Neuropsychiatr 2013 25:128-136.

12. Gresa-Arribas N, Arino H, Martinez-Hernandez E, et al. Antibodies to inhibitory synaptic proteins in neurological syndromes associated with glutamic acid decarboxylase autoimmunity. PLoS One 2015;10: e0121364.

13. Jansen C, Parchi P, Capellari S, et al. Prion protein amyloidosis with divergent phenotype associated with two novel nonsense mutations in PRNP. Acta Neuropathol 2010;119:189-197.
14. van Coevorden-Hameete MH, de Graaff E, Titulaer MJ, Hoogenraad CC, Sillevis Smitt PA. Molecular and cellular mechanisms underlying anti-neuronal antibody mediated disorders of the central nervous system. Autoimmun Rev 2014;13:299-312.

15. Graus F, Delattre JY, Antoine JC, et al. Recommended diagnostic criteria for paraneoplastic neurological syndromes. J Neurol Neurosurg Psychiatry 2004;75: $1135-1140$.

16. Gresa-Arribas N, Titulaer MJ, Torrents A, et al. Antibody titres at diagnosis and during follow-up of anti-NMDA receptor encephalitis: a retrospective study. Lancet Neurol 2014; 13:167-177.

17. Hoftberger R, van Sonderen A, Leypoldt F, et al. Encephalitis and AMPA receptor antibodies: novel findings in a case series of 22 patients. Neurology 2015;84: 2403-2412.

18. Hoftberger R, Titulaer MJ, Sabater L, et al. Encephalitis and $\mathrm{GABAB}$ receptor antibodies: novel findings in a new case series of 20 patients. Neurology 2013;81: 1500-1506.

19. Paterson RW, Torres-Chae CC, Kuo AL, et al. Differential diagnosis of Jakob-Creutzfeldt disease. Arch Neurol 2012;69:1578-1582.

20. Vitali P, Maccagnano E, Caverzasi E, et al. Diffusionweighted MRI hyperintensity patterns differentiate CJD from other rapid dementias. Neurology 2011;76: 1711-1719.

21. Geschwind MD, Shu H, Haman A, Sejvar JJ, Miller BL. Rapidly progressive dementia. Ann Neurol 2008;64:97-108.

22. Papageorgiou SG, Kontaxis T, Bonakis A, Karahalios G, Kalfakis N, Vassilopoulos D. Rapidly progressive dementia: causes found in a Greek tertiary referral center in Athens. Alzheimer Dis Assoc Disord 2009;23: 337-346.

23. Sala I, Marquie M, Sanchez-Saudinos MB, et al. Rapidly progressive dementia: experience in a tertiary care medical center. Alzheimer Dis Assoc Disord 2012;26: 267-271.

24. Flanagan EP, McKeon A, Lennon VA, et al. Autoimmune dementia: clinical course and predictors of immunotherapy response. Mayo Clin Proc 2010;85:881-897.

25. Lancaster E, Dalmau J. Neuronal autoantigens: pathogenesis, associated disorders and antibody testing. Nat Rev Neurol 2012;8:380-390.

26. Lai M, Huijbers MG, Lancaster E, et al. Investigation of LGI1 as the antigen in limbic encephalitis previously attributed to potassium channels: a case series. Lancet Neurol 2010;9:776-785.

27. Irani SR, Alexander S, Waters P, et al. Antibodies to Kv1 potassium channel-complex proteins leucine-rich, glioma inactivated 1 protein and contactin-associated protein-2 in limbic encephalitis, Morvan's syndrome and acquired neuromyotonia. Brain 2010;133: 2734-2748.

28. Lancaster E, Huijbers MG, Bar V, et al. Investigations of caspr2, an autoantigen of encephalitis and neuromyotonia. Ann Neurol 2011;69:303-311.

29. Tuzun E, Zhou L, Baehring JM, Bannykh S, Rosenfeld MR, Dalmau J. Evidence for antibodymediated pathogenesis in anti-NMDAR encephalitis associated with ovarian teratoma. Acta Neuropathol 2009;118: 737-743. 
30. Martinez-Hernandez E, Horvath J, Shiloh-Malawsky Y, Sangha N, Martinez-Lage M, Dalmau J. Analysis of complement and plasma cells in the brain of patients with anti-NMDAR encephalitis. Neurology 2011;77: 589-593.

31. Bien CG, Vincent A, Barnett MH, et al. Immunopathology of autoantibody-associated encephalitides: clues for pathogenesis. Brain 2012;135:1622-1638.
32. Bernal F, Graus F, Pifarre A, Saiz A, Benyahia B, Ribalta T. Immunohistochemical analysis of anti-Huassociated paraneoplastic encephalomyelitis. Acta Neuropathol 2002;103:509-515.

33. Blumenthal DT, Salzman KL, Digre KB, Jensen RL, Dunson WA, Dalmau J. Early pathologic findings and long-term improvement in anti-Ma2-associated encephalitis. Neurology 2006;67:146-149. 


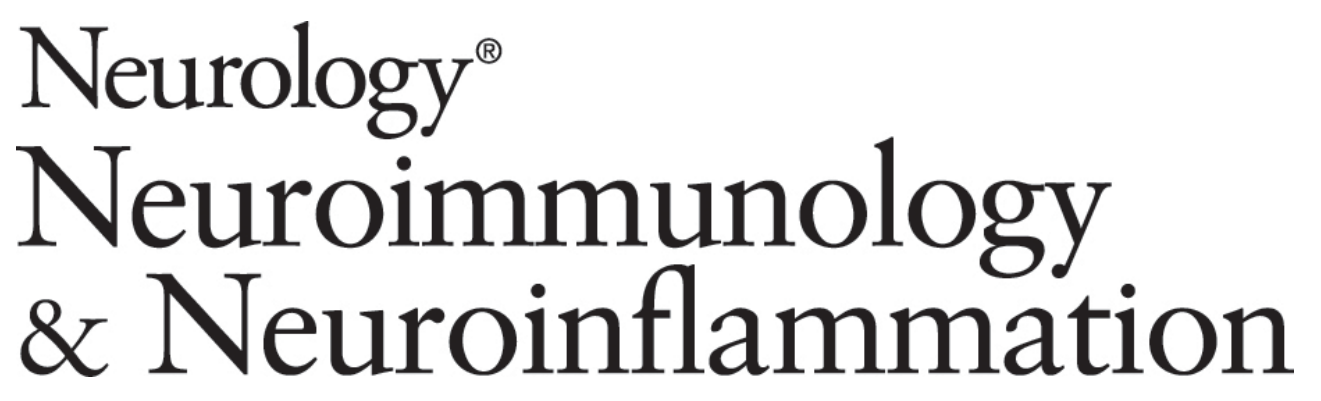
Pathologically confirmed autoimmune encephalitis in suspected Creutzfeldt-Jakob disease
Peter Maat, Janet W. de Beukelaar, Casper Jansen, et al.
Neurol Neuroimmunol Neuroinflamm 2015;2;
DOI 10.1212/NXI.0000000000000178

This information is current as of November 12, 2015

Neurol Neuroimmunol Neuroinflamm is an official journal of the American Academy of Neurology.

Published since April 2014, it is an open-access, online-only, continuous publication journal. Copyright $\odot$ 2015 American Academy of Neurology. All rights reserved. Online ISSN: 2332-7812.

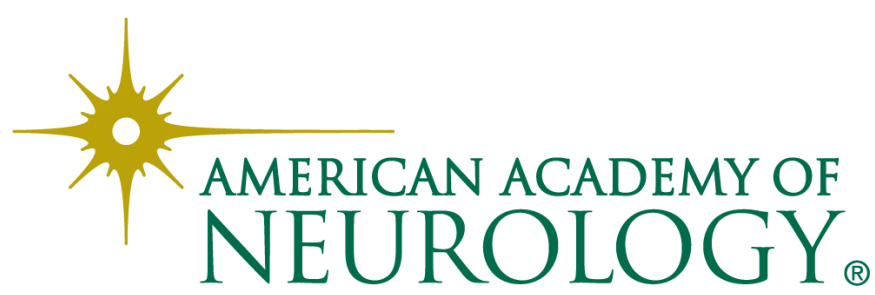




\section{Updated Information \& Services}

\section{Supplementary Material}

\section{References}

Citations

Subspecialty Collections

\section{Permissions \& Licensing}

Reprints including high resolution figures, can be found at: http://nn.neurology.org/content/2/6/e178.full.html

Supplementary material can be found at: http://nn.neurology.org/content/suppl/2015/11/12/2.6.e178.DC1

This article cites 33 articles, 2 of which you can access for free at: http://nn.neurology.org/content/2/6/e178.full.html\#\#ref-list-1

This article has been cited by 8 HighWire-hosted articles: http://nn.neurology.org/content/2/6/e178.full.html\#\#otherarticles

This article, along with others on similar topics, appears in the following collection(s):

\section{All Cognitive Disorders/Dementia}

http://nn.neurology.org//cgi/collection/all_cognitive_disorders_dementi a

\section{Autoimmune diseases}

http://nn.neurology.org//cgi/collection/autoimmune_diseases

\section{Paraneoplastic syndrome}

http://nn.neurology.org//cgi/collection/paraneoplastic_syndrome

\section{Prion}

http://nn.neurology.org//cgi/collection/prion

Information about reproducing this article in parts (figures,tables) or in its entirety can be found online at:

http://nn.neurology.org/misc/about.xhtml\#permissions

Information about ordering reprints can be found online: http://nn.neurology.org/misc/addir.xhtml\#reprintsus

Neurol Neuroimmunol Neuroinflamm is an official journal of the American Academy of Neurology.

Published since April 2014, it is an open-access, online-only, continuous publication journal. Copyright $\odot$ 2015 American Academy of Neurology. All rights reserved. Online ISSN: 2332-7812.

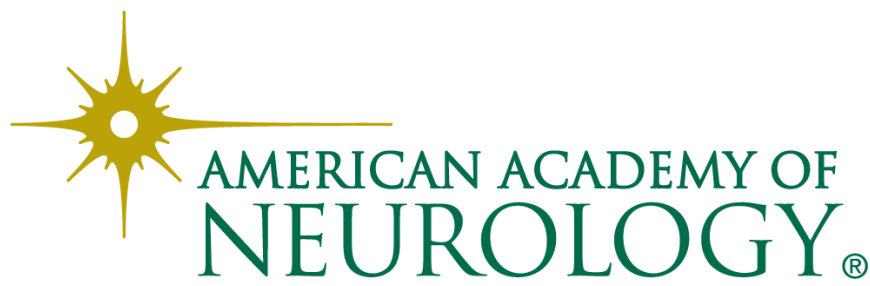

